\title{
Clinical significance of Phosphatidyl Inositol Synthase overexpression in oral cancer
}

\author{
Jatinder Kaur ${ }^{\dagger 1}$, Meenakshi Sawhney ${ }^{\dagger 1}$, Siddartha DattaGupta², Nootan K Shukla ${ }^{3}$, Anurag Srivastava ${ }^{4}$ and \\ Ranju Ralhan*1,5,6,7,8,9
}

\begin{abstract}
Background: We reported increased levels of Phosphatidyl Inositol synthase (PI synthase), (enzyme that catalyses phosphatidyl inositol (PI) synthesis-implicated in intracellular signaling and regulation of cell growth) in smokeless tobacco (ST) exposed oral cell cultures by differential display. This study determined the clinical significance of PI synthase overexpression in oral squamous cell carcinoma (OSCC) and premalignant lesions (leukoplakia), and identified the downstream signaling proteins in PI synthase pathway that are perturbed by smokeless tobacco (ST) exposure.

Methods: Tissue microarray (TMA) Immunohistochemistry, Western blotting, Confocal laser scan microscopy, RT-PCR were performed to define the expression of PI synthase in clinical samples and in oral cell culture systems.

Results: Significant increase in PI synthase immunoreactivity was observed in premalignant lesions and OSCCs as compared to oral normal tissues $(p=0.000)$. Further, PI synthase expression was significantly associated with dedifferentiation of OSCCs, $(p=0.005)$ and tobacco consumption $(p=0.03, O R=9.0)$. Exposure of oral cell systems to smokeless tobacco (ST) in vitro confirmed increase in PI synthase, Phosphatidylinositol 3-kinase (PI3K) and cyclin D1 levels.
\end{abstract}

Conclusion: Collectively, increased PI synthase expression was found to be an early event in oral cancer and a target for smokeless tobacco.

\section{Background}

Five percent of all cancers occur in the head and neck, with over 500,000 cases reported annually worldwide, and mortality rate of about 50\% [1-3]; approximately half of these occur in the oral cavity [4]. Head-and-neck cancer sites are readily amenable to clinical examination, yet a lack of suitable molecular markers for early detection and risk assessment is clearly reflected by the fact that more than $50 \%$ of all oral squamous cell carcinoma (OSCC) patients have advanced disease at the time of diagnosis $[1,3,5,6]$. Indeed, the five-year survival rates of OSCC patients are in general poor (about $50 \%$ overall) and the prognosis of advanced OSCC cases has not improved much over the past three decades [3,5]. Epidemiological evidence shows a correlation between use of smokeless tobacco (ST) and lesions of the oral cavity as

\footnotetext{
* Correspondence: ralhanr@yorku.ca

1 Department of Biochemistry, All India Institute for Medical Sciences, Ansari

Nagar, New Delhi -110029, India

+ Contributed equally

Full list of author information is available at the end of the article
}

well as with incidence of oral cancer [7-9]. OSCCs are often preceded by clinically evident oral lesions (OLs), often leukoplakia, and the risk of multiple cancers is 5-10 times greater in patients with OSCCs preceded by leukoplakia [10]. These OLs are reported to be more common in chewing tobacco related oral cancer in India [11].

Intense efforts are being directed towards developing accurate predictors of clinical outcome using high throughput techniques such as differential displayreverse transcription PCR (DD), cDNA microarrays and proteomics to assess global gene/protein expression patterns in head and neck cancer [12-15]. In search of such novel molecular targets, our laboratory reported increased levels of phosphatidyl inositol synthase (PI Synthase) or CDP-diacylglycerol-inositol 3-phosphatidyl transferase (CDIPT) transcripts in cell cultures from a human oral lesion (AMOL), exposed to ST extracts using DD [16], providing the rationale for in-depth investigation of biological and clinical significance of its expression in oral cancer. 
PI Synthase (PIS) (EC 2.7.8.11) is a 24-kDa membranebound enzyme, which catalyzes the last step in the de novo biosynthesis of phosphatidylinositol (PI) by catalyzing the condensation of CDP-diacylglycerol and myoinositol to form PI and CMP. PI is involved in protein membrane anchoring, and is the precursor for the second messengers- inositol-tri-phosphate and diacylglycerol (DG). These ubiquitous second messengers function downstream of many $\mathrm{G}$ protein-coupled receptors and tyrosine kinases regulating cell growth, calcium metabolism, and PKC activity. The biological role of PI is of considerable interest due to the involvement of PI and its phosphorylated derivatives in intracellular signal transduction. Phosphatidylinositol 3-kinase (PI3K) catalyses the phosphorylation of PI in the $3-\mathrm{OH}$ position of the inositol ring. The PI3K pathway regulates various cellular processes, such as proliferation, growth, apoptosis and cytoskeletal rearrangement $[17,18]$.

Herein, we determined the effect of ST on the expression PI Synthase and its downstream targets PI3K and cyclinD1 in oral cell systems. Further, we investigated the clinical significance of PI Synthase expression in oral cancer using immunohistochemistry.

\section{Methods}

\section{Cell culture}

Human head and neck squamous carcinoma cell lines, HSC2, SCC-4 and cell culture from an oral lesion (OL), AMOL [19], were grown in monolayer cultures in Dulbecco's modified eagle medium (DMEM) and Ham F-12 (DMEM-F12) (Sigma, MO) supplemented with $10 \%$ fetal bovine serum (FBS), $2.5 \mathrm{mM}$ L-glutamine, $1 \times$ sodium pyruvate (supplied as $100 \times$ stock with a concentration of $11,004 \mathrm{mg} / \mathrm{L}$ ), $1 \mathrm{mM}$ NEAA (non-essential amino acids), $100 \mu \mathrm{g} / \mathrm{ml}$ streptomycin and $100 \mathrm{U} / \mathrm{ml}$ penicillin in a humidified incubator (5\% carbon-dioxide, 95\% air) at $37^{\circ} \mathrm{C}$ as described previously [19].

\section{Treatments with Smokeless Tobacco Extract}

Aqueous extracts of ST were prepared and standardized from batch to batch by measuring the nicotine content as described by us previously [19]. Cells (1000 cells/well) were plated in 96 well plates and allowed to grow for $24 \mathrm{~h}$ in complete medium. After $24 \mathrm{~h}$, cells were treated with different concentrations $(1-1000 \mu \mathrm{g} / \mathrm{ml}$ range) of ST for different time intervals 4, 12, 24, 48, 72 and $120 \mathrm{~h}$, with STE replenished every $24 \mathrm{~h}$. Cell viability was assessed using MTT assay as described earlier [19]. Cells were treated with ST $(10 \mu \mathrm{g} / \mathrm{ml}, 48 \mathrm{hrs})[20,21]$ and harvested thereafter for western blotting/RT-PCR analysis/immunofluorescence.

\section{Western blotting}

Whole cell lysates were prepared from untreated (control) and ST-treated AMOL, HSC2 and SCC-4 cells. Pro- tein concentrations were determined using Bradford reagent (Sigma) and equal amounts of proteins from untreated and treated cells were resolved on $10 \%$ sodium dodecyl sulphate (SDS)-polyacrylamide gels. The proteins were then electro-transferred onto polyvinylidenedifluoride (PVDF) membrane. After blocking with 10\% non-fat milk in Tris-buffered saline (TBS, $0.1 \mathrm{M}, \mathrm{pH}=$ 7.4), blots were incubated with anti-PI Synthase antibody (a kind gift from Dr. Jackowski, St. JudeChildren's hospital, Tennesee, Memphis) or anti PI-3kinase or anti-cyclin D1 antibody (Santa Cruz Biotechnology Inc., Santacruz, CA) (dilution $1: 200$ ) at $4^{\circ} \mathrm{C}$ overnight. Protein abundance of $\alpha$-tubulin served as a control for protein loading, and was determined with mouse monoclonal anti- $\alpha$-tubulin antibody (Santa Cruz Biotechnology, CA). Membranes were incubated with secondary antibody, HRP-conjugated goat/mouse anti-IgG (Dako CYTOMATION, Denmark), at an appropriate dilution in 1\% BSA, for $2 \mathrm{~h}$ at room temperature. After each step blots were washed thrice with Tween (0.1\%)-Tris-buffered saline (TTBS). Protein bands were detected by enhanced chemiluminescence method (ECL, Amersham, Buckinghamshire, UK) on XO-MAT film.

\section{Confocal laser scan microscopy}

Cells (AMOL and HSC2) grown on coverslips were treated with ST $(10 \mu \mathrm{g} / \mathrm{ml}, 48 \mathrm{hrs})$ in DMEM-F12 medium supplemented with $2 \% \mathrm{FBS}$ at $37^{\circ} \mathrm{C}$ and processed for confocal laser scan microscopy as described by us $[21,22]$.

\section{Tissue specimens}

This study was approved by Human Ethics Committee of All India Institute of Medical Sciences, New Delhi, India. For immunohistochemical analysis surgically resected tissues or biopsy specimens from OSCCs, OLs and normal oral tissues were obtained from Surgical Oncology Unit of Dr. B.R. Ambedkar Institute Rotary Cancer Hospital, All India Institute of Medical Sciences, New Delhi, India, with prior consent of the patients. The clinical and pathological data recorded included clinical tumor stage, site of the lesion, histopathological differentiation, age, gender and, tobacco and alcohol consumption habits in a pre-designed performa as described by us previously [23]. Clinicopathological characteristics of patients

Twenty one OSCC patients, ranging in age from 29 to 75 years were enrolled in this study. The diagnosis was based on clinical examination and histopathological analysis of the tissue specimens. The tumors were histologically graded as well, moderately or poorly differentiated SCCs. Twenty oral lesions were included in this study. The histopathological assessment scoring based on the architectural and cytological changes of epithelial dysplasia as described in the WHO classification and recently reviewed [24]. Oral lesions/leukoplakia (13 cases) were classified in two groups: (i) OLs with no dysplasia, (ii) 
OLs with dysplasia. Seven tissues taken from a distant site of OSCCs (with histologically confirmed normal oral epithelium hither to referred to as oral normal tissues) were also evaluated for PI Synthase protein expression.

\section{Tissue Microarray Immunohistochemistry}

Oral squamous cancer Tissue Microarray (TMA) with 60 oral tissue sections (IMT-01250) was procured from Imgenex India Ltd (Bhubaneshwar, Orissa, India). Of the 60 oral tissue sections in TMA, 49 were OSCCs, 8 were oral lesions and 3 were non-malignant oral tissues. In addition, paraffin embedded sections ( $5 \mu \mathrm{m}$ thickness) of human oral tissue specimens ( 21 OSCCs, 12 oral lesions and 7 non-malignant oral tissues) were stained with hematoxylin and eosin for histopathological analysis, and immunostaining was done on serial sections individually as described previously by Arora et al. [23]. The TMA slide and the individual tissue sections were de-paraffinized by baking at $62^{\circ} \mathrm{C}$ for 1 hour in vertical orientation and rehydrated prior to antigen retrieval. Thereafter, antigen retrieval was carried out using a microwave oven in $0.01 \mathrm{M}$-citrate buffer, $\mathrm{pH}$ 6.0. Endogenous peroxidase activity was blocked by incubating sections in methanol containing hydrogen peroxide $(0.3 \%, \mathrm{v} / \mathrm{v})$ for $20 \mathrm{~min}$. Non-specific binding was blocked with $1 \%(\mathrm{w} / \mathrm{v}) \mathrm{BSA}$ in PBS for $1 \mathrm{~h}$ and incubated with anti-PI Synthase antibody (1:200 dilution) for $16 \mathrm{~h}$ at $4^{\circ} \mathrm{C}$. The primary antibody was detected using biotinylated secondary antibody and peroxidase labeled Streptavidin complex using Dako LSAB plus kit (Dako Labs, Glostrup, Denmark) and diaminobenzidine (DAB) as chromogen.

\section{Positive criterion for immunohistochemical staining}

The immunopositive staining was evaluated in randomly selected five non-overlapping areas of the tissue sections with more than $80 \%$ epithelial cells. PI Synthase cytoplasmic immunoreactivity was classified into five categories, defined as follows: (0), 1 immunostaining in $<10 \%$ cells; $(+1)$, immunostaining in $10-30 \%$ cells; $(+2)$, immunostaining in $30-50 \%$ cells; $(+3)$, immunostaining in $50-70 \%$ cells and $(+4)$, immunostaining in $>70 \%$ of the cells showing cytoplasmic staining. Intensity was graded into four categories, defined as follows: (0), no detectable immunostaining or basal immunostaining; (+1) mild; (+2) moderate and $(+3)$ intense immunostaining. The final score was calculated by adding the percentage positivity and intensity of staining scores (range $0-7$ ). The immunohistochemical investigation was blind, i.e. the slides were coded and pathologist did not have prior knowledge of the local tumor burden, lymphonodular spread and grading of the OSCCs while scoring the immunoreactivity.

\section{Statistical analysis}

The immunohistochemical data were subjected to statistical analysis using SPSS 10.0 software (Chicago). Box plot was prepared to determine the distribution of total score of PI Synthase protein expression in normal oral tissues, OLs and OSCCs. The performance of a diagnostic variable can be quantified by calculating the area under the ROC (receiver operating characteristic) curve. A graph of sensitivity against 1-specificity is called ROC curve. Sensitivity of a diagnostic test is the proportion of patients for whom the outcome is positive that is correctly identified by the test. Specificity is the proportion of patients for whom the outcome is negative that are correctly identified by the test. The ideal test would have an area under the ROC curve of 1 , whereas a random guess would have an area under the ROC curve of 0.5 . A better predictive power is attributed to a diagnostic variable as it approaches 1. ROC curve was plotted for PI Synthase for normal vs. OPLs, and normals Vs OSCCs using the final score obtained as described above. Sensitivity and specificity were calculated and quantified using receiver operating characteristic (ROC) analyses. Based on sensitivity and specificity values for PI Synthase, a cut-off $\geq 3$ was defined as positive criterion for PI Synthase immunopositivity for statistical examination. The relationships between PI Synthase expression and clinicopathological parameters was tested in univariate analysis by ChiSquare and Fisher's exact test Two sided p-values were calculated and $\mathrm{p} \leq 0.05$ was considered to be significant.

\section{Results}

To determine the biological significance of PI Synthase, we investigated the effect of ST on induction of this enzyme using oral cancer cell lines and oral epithelial cell cultures [19].

\section{Smokeless Tobacco activates PI Synthase in oral epithelial cell cultures}

To determine the optimal dose and duration for ST treatment, AMOL and HSC-2 cells were treated with different concentrations of ST ranging from $1 \mu \mathrm{g} / \mathrm{ml}$ to $1000 \mu \mathrm{g} / \mathrm{ml}$ for varying time periods ranging from $4 \mathrm{~h}$ to $120 \mathrm{~h}$. Cell viability was measured by MTT assay. HSC-2 cells showed $25 \%$ increase in cell proliferation at $10 \mu \mathrm{g} / \mathrm{ml}$ concentration of ST after $48 \mathrm{~h}$ and $60 \%$ increase in cell proliferation at $10 \mu \mathrm{g} / \mathrm{ml}$ concentration of ST after $72 \mathrm{~h}$. AMOL cells showed $20 \%$ increase in cell proliferation at $10 \mu \mathrm{g} / \mathrm{ml}$ concentration of ST after $48 \mathrm{~h}$. Since higher doses were toxic for AMOL and HSC-2 cells, we chose 10 $\mu \mathrm{g} / \mathrm{ml}$ of ST as the optimal dose for assessing the changes in protein expression levels upon enhanced cell proliferation. AMOL cells [19] were treated with $10 \mu \mathrm{g} / \mathrm{ml}$ of ST for varying time points. Untreated (control) AMOL cells expressed basal levels of PI Synthase (Figure 1). Treatment of AMOL cells with ST showed increase in PI Synthase expression within $6 \mathrm{~h}$; while 2 fold enhanced expression was observed in $48 \mathrm{~h}$ (Figure 1). Hence, $10 \mu \mathrm{g} /$ 


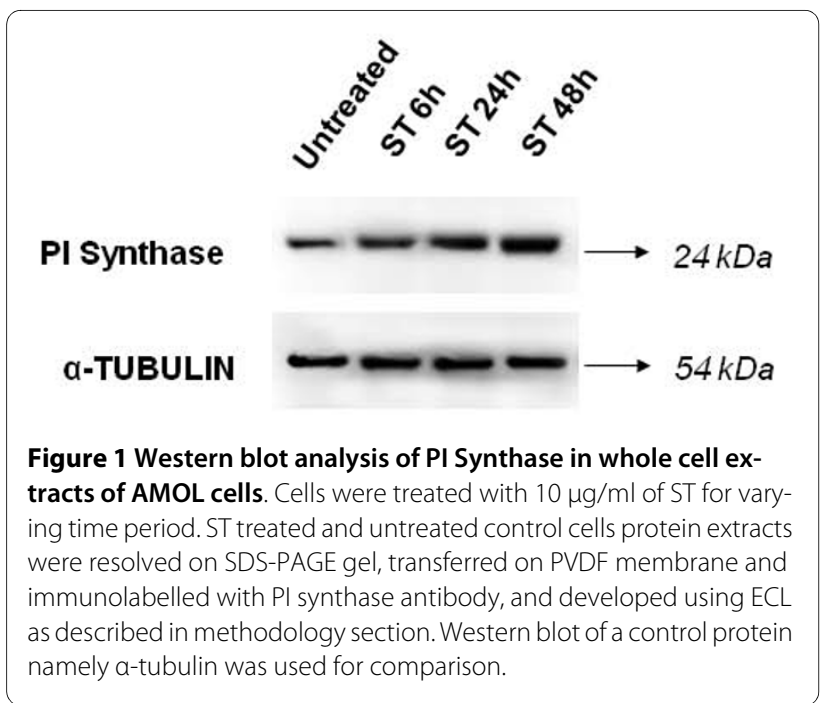

$\mathrm{ml} \mathrm{ST}$ for $48 \mathrm{~h}$ was chosen for further experiments in oral cells. PI Synthase expression was analysed in AMOL and HSC- 2 cells treated with ST $(10 \mu \mathrm{g} / \mathrm{ml})$ for $48 \mathrm{~h}$ by immunocytochemistry using a confocal microscope. Increased cytoplasmic expression of PI Synthase protein was observed in ST treated AMOL and HSC-2 cells as compared to the untreated control cells which expressed only basal levels of PI Synthase protein (Figures 2 and 3 respectively).

\section{Smokeless Tobacco induces PI3K and Cyclin D1 expression} in oral cell cultures

Basal expression of PI3K was observed in both AMOL and HSC-2 cells (Figures 2 and 3 respectively). Treatment of cells with ST resulted in increased cytoplasmic expression of PI3-K protein (Figures 2 and 3 respectively) and cyclin D1 (Figures 2 and 3 respectively) in both cell types as compared to the untreated control cells, suggesting that ST induced PI Synthase expression, is accompanied by the induction of PI3-K and cyclin D1 in cultures established form OLs and OSCCs.

The immunostaining findings were corroborated by western blot analysis: untreated AMOL, HSC-2 and SCC4 cells expressed basal levels of PI Synthase protein (Figure 4, lane Untreated), while ST treatment resulted in increased expression of PI Synthase protein in AMOL (1.9 folds; Figure 4, lane ST), HSC-2 cells ( 2 folds; Figure 4, lane ST) and SCC-4 cells (2 folds; Figure 4, lane ST).

A $65 \mathrm{kDa}$ band of PI3K protein was detected in cytoplasmic extracts of untreated AMOL, HSC-2 and SCC-4 cells (Figure 4). ST treatment increased the levels of PI3K protein in AMOL (1.8 folds), HSC-2 (2.1 folds) and SCC4 (2 folds) cells (Figure 4). Further, exposure to ST resulted in increased expression of cyclin D1 protein in AMOL (2.4 folds), HSC-2 (2 folds) and SCC-4 cells (1.9 folds) as compared to the untreated control cells (Figure $4)$.

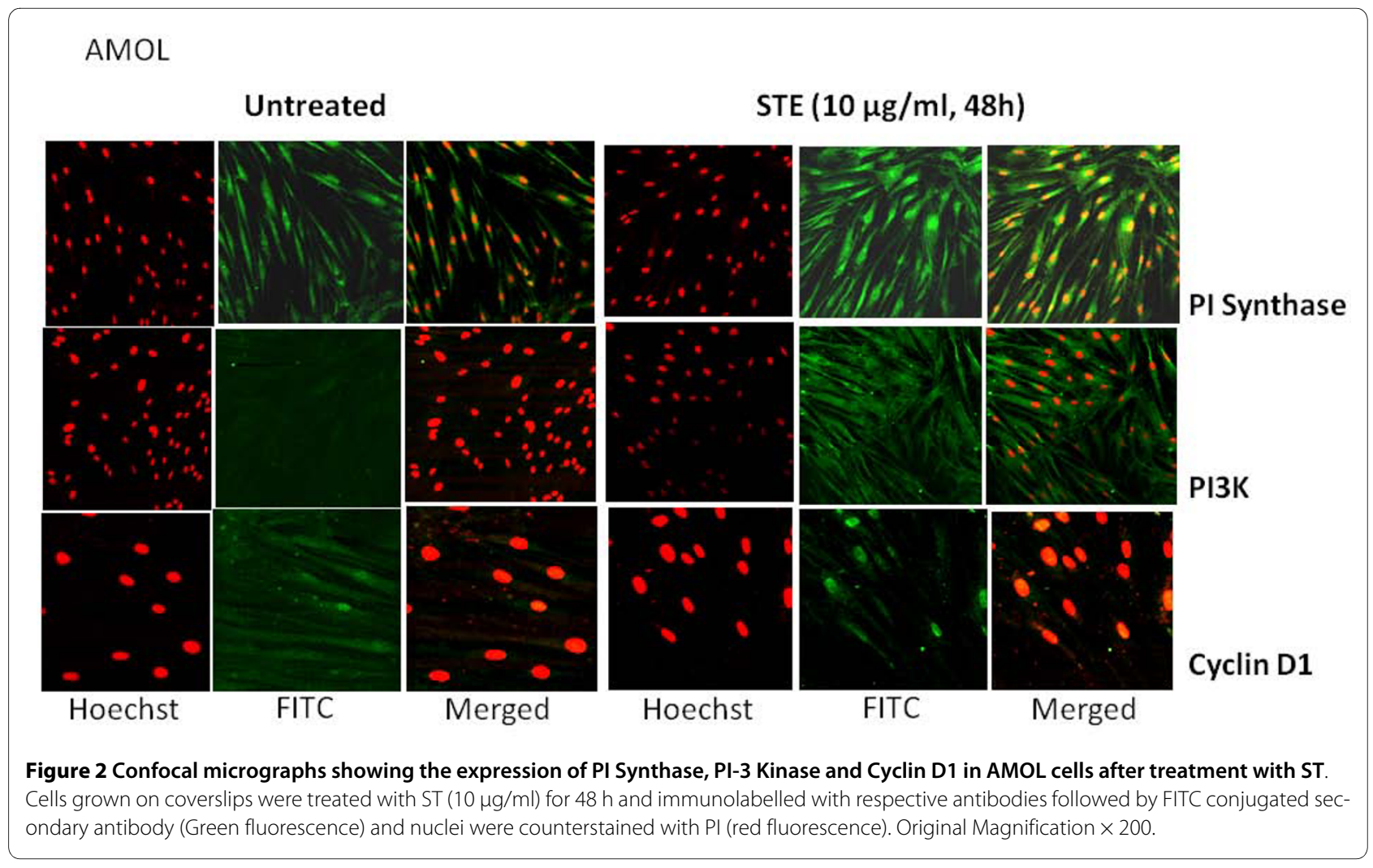


HSC-2

Untreated
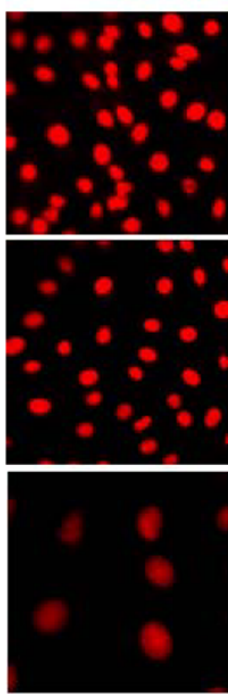

Hoechst
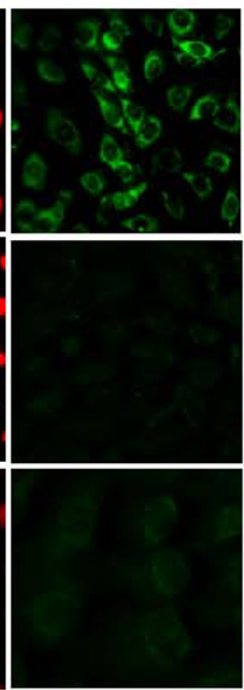

FITC
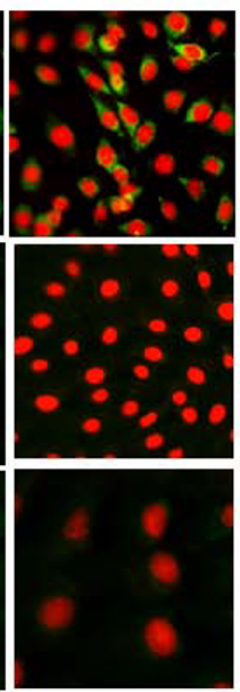

Merged

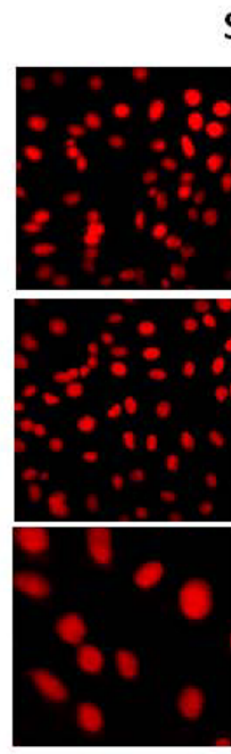

Hoechst
STE $(10 \mu \mathrm{g} / \mathrm{ml}, 48 \mathrm{~h})$
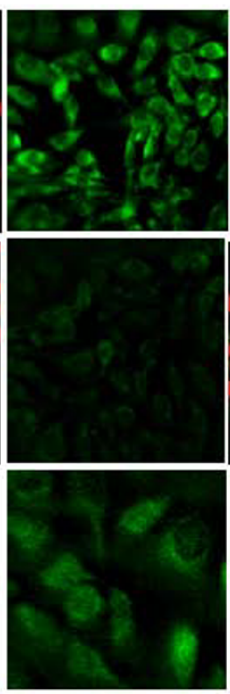

FITC
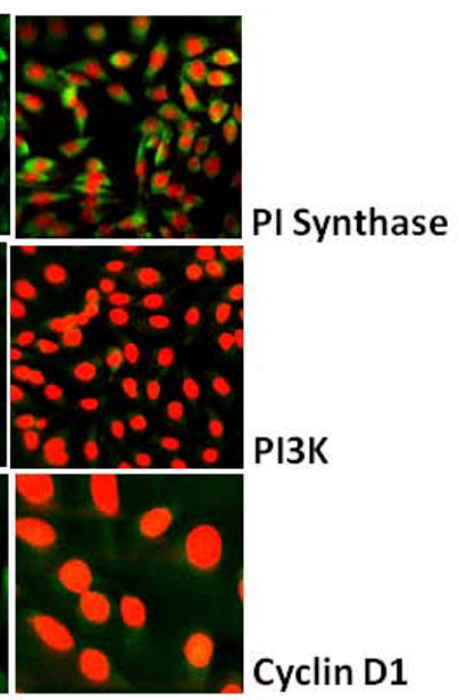

Merged

Figure 3 Confocal micrographs showing the expression of PI Synthase, PI-3 Kinase and Cyclin D1 in HSC-2 cells after treatment with ST. Cells grown on coverslips were treated with ST $(10 \mu \mathrm{g} / \mathrm{ml})$ for $48 \mathrm{~h}$ and immunolabelled with respective antibodies followed by FITC conjugated secondary antibody (Green fluorescence) and nuclei were counterstained with PI (red fluorescence). Original Magnification $\times 200$.

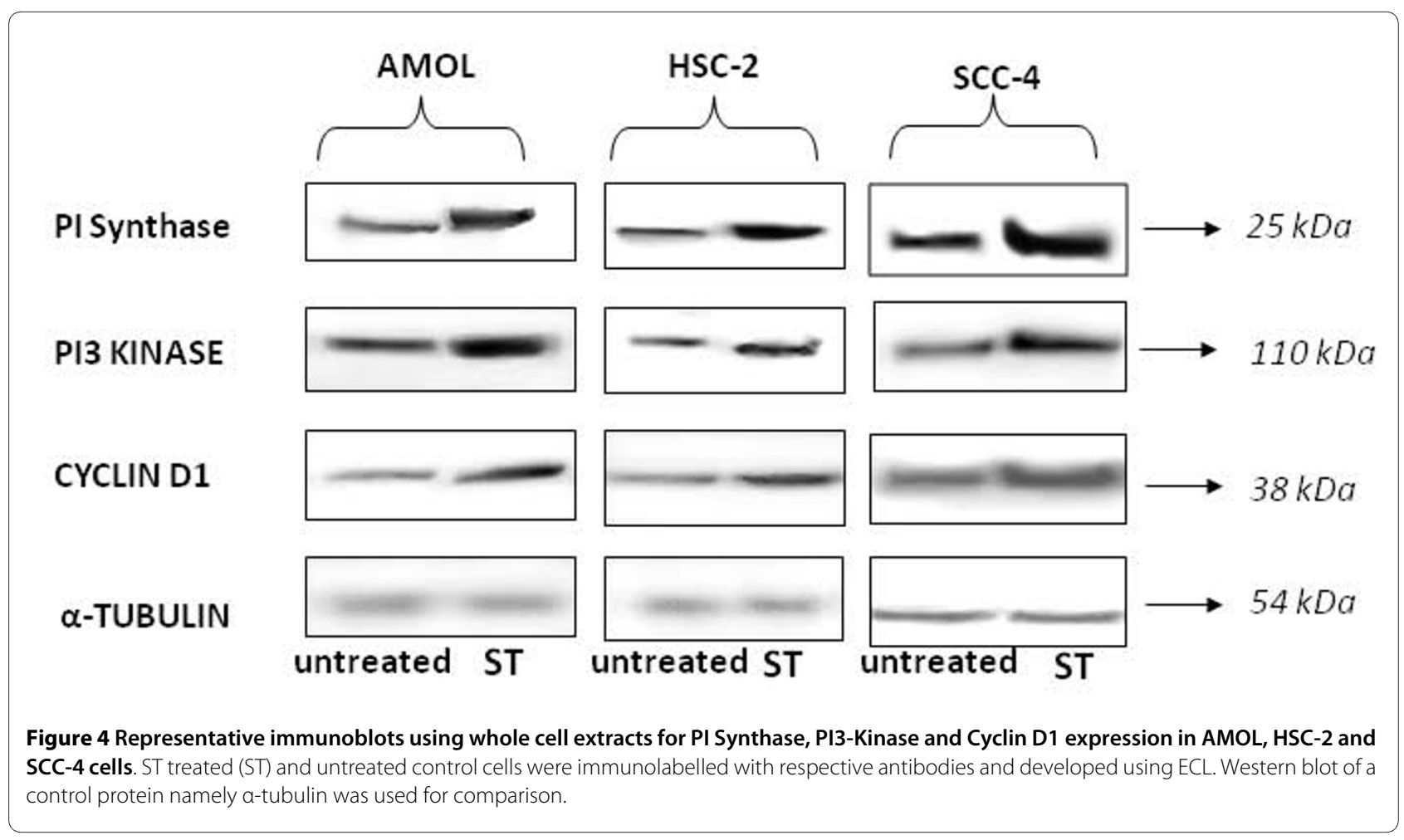




\section{OSCCs and clinical correlations}

Immunohistochemical analysis of PI Synthase was performed in individual sections of 21 OSCCs, 13 OLs and 7 histologically normal oral tissues. In addition, immunohistochemical analysis of PI Synthase was performed in OSCCs in a TMA format (Figure 4). Histologically proven normal oral tissue showed no detectable expression of PI Synthase protein (Figure 5). Cytoplasmic immunostaining was observed in OLs with no dysplasia (Figure 5). Intense cytoplasmic PI Synthase immunostaining was observed in dysplastic and OSCC lesions (Figure 5).

The results of immunohistochemical analysis of PI Synthase expression in normal oral tissues (10), OLs (20), and OSCCs (70); their correlation with clinicopathological parameters and tobacco consumption habits of the patients are summarized in Table 1. PI Synthase protein was localized predominantly in cytoplasm of epithelial cells. PI Synthase expression was observed in 16/20 (80\%) OLs and 61/70 (87\%) OSCCs. Increased expression of PI Synthase protein was observed in OLs and OSCCs as compared to normal (histologically non-malignant) oral tissues as shown in the Box plot analysis in Figure 6. Significant increase in PI Synthase expression was observed in OLs with no dysplasia, dysplasia and OSCC ( $\mathrm{p}=$ 0.000). In OSCC patients, PI Synthase expression was significantly associated with tumor dedifferentiation (WDSCCs vs. MDSCCs and PDSCCs; $\mathrm{p}=0.005$ ) and tobacco consumption habits $(\mathrm{p}=0.03)$. Figure 7 depicts $25-\mathrm{kDa}$ band of PI Synthase protein in representative normal oral tissues, OLs and OSCCs obtained by western blot analysis.

\section{Evaluation of PI Synthase as a potential biomarker}

Receiver Operating Characteristic (ROC) analysis was used to determine the potential of PI Synthase as a biomarker for diagnosis of leukoplakia and OSCCs. The area-under-the-curve (AUC) values were 0.882 and 0.964 for normal versus OLs (Figure 8a) and OSCCs (Figure $8 \mathrm{~b})$, respectively indicating that PI Synthase may have the potential as a diagnostic biomarker for leukoplakia and OSCCs.

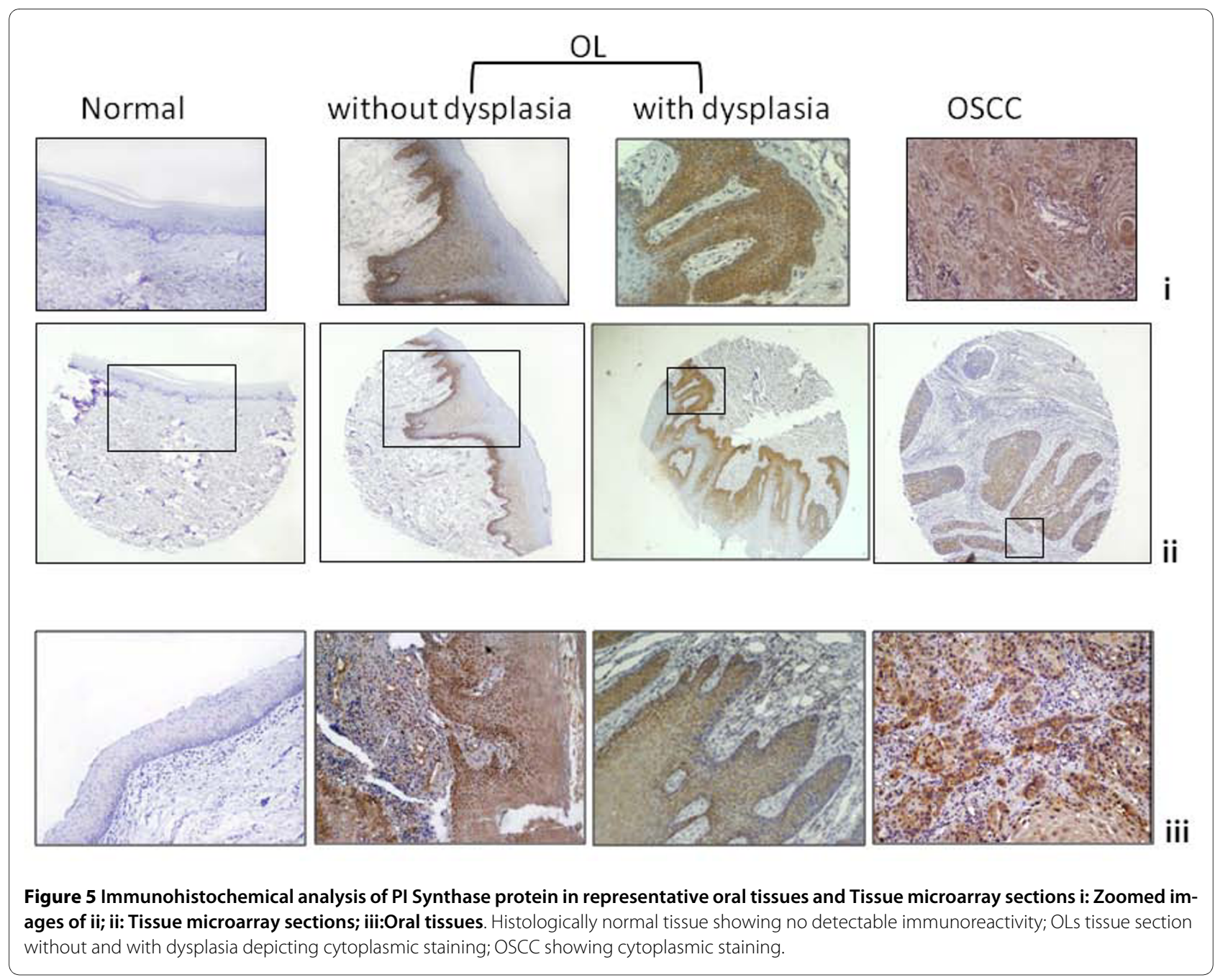




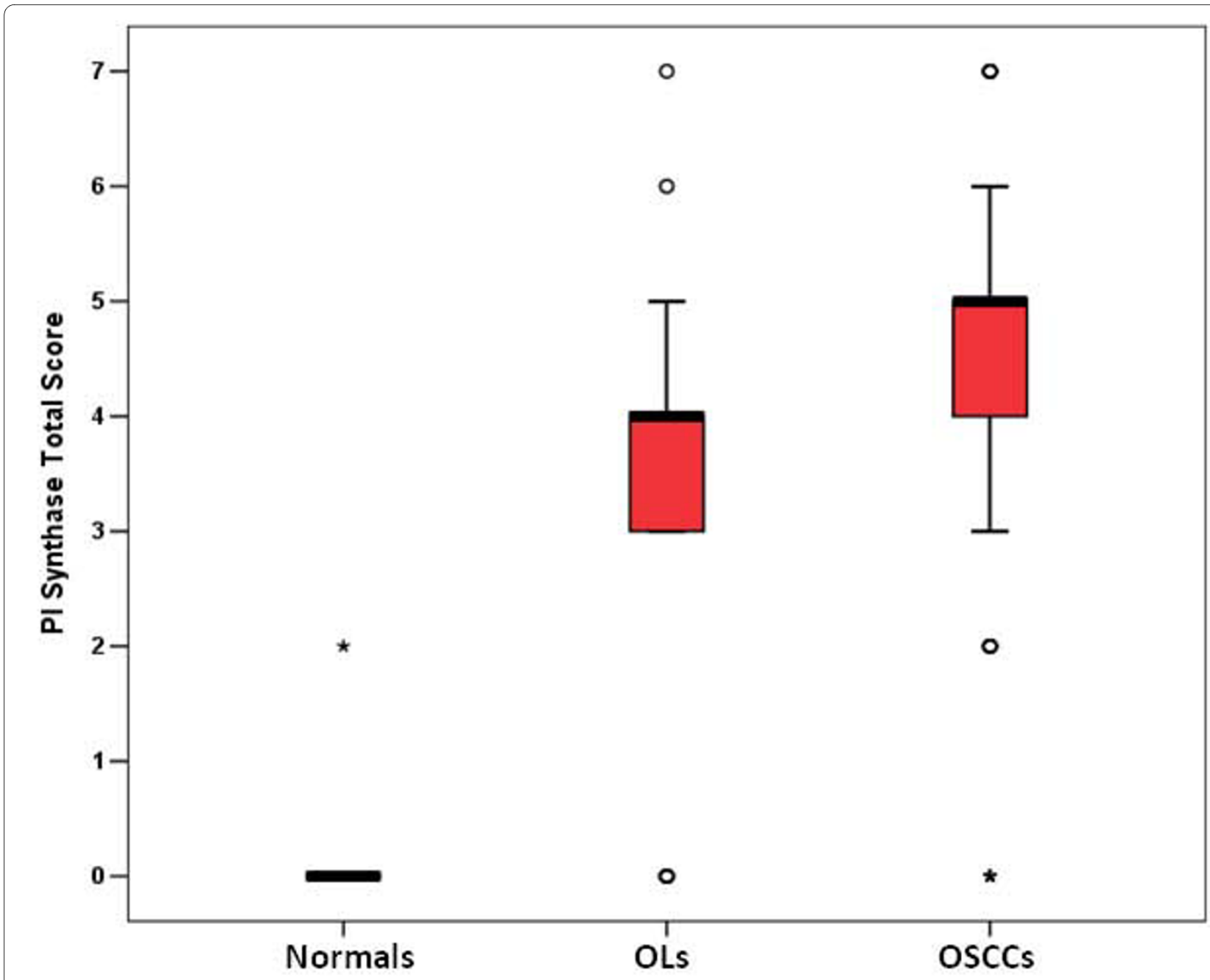

Figure 6 Box-Plot analysis. Box plots showing distribution of total immunostaining scores of PI Synthase protein determined by immunohistochemistry in paraffin-embedded sections of normal oral tissues, OLs and OSCCs. The vertical axis gives the total immunostaining score, obtained as described in the Methods section. Box plots showed increased expressions of PI Synthase in OSCCs with a median score (bold horizontal line) of 5 (range 3--6, as shown by vertical bars), as compared to non-malignant (histologically normal) oral tissues with a median score of 0.

\section{Discussion}

This study, to our knowledge, is the first report demonstrating overexpression of PI Synthase, PI3-K and cyclin D1 in ST treated cells from oral lesions and oral cancer.

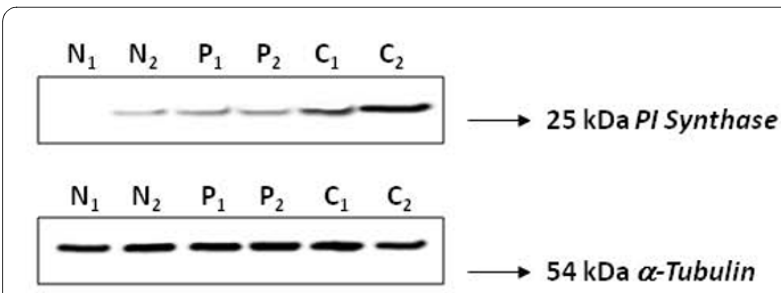

Figure 7 Representative western blot for PI Synthase protein in oral tissues. normal oral tissues (lane N1, N2); OPLs (lane P1, P2) and OSCCs (lane C1, C2) depicting a-tubulin used as a control protein
Analyzing clinical specimens from oral leukoplakic lesions without dysplasia, with dysplasia and OSCCs, we provide the first evidence of increased expression of PI Synthase in early stages of oral precancer and cancer and its correlation with tumor dedifferentiation and tobacco consumption.

High PI Synthase activity has been observed in $s r c$ - and erbB2-transformed cells regulated by tyrosine kinase [25]; moreover, PI synthesis could be stimulated by addition of mitogenic growth factors and serum in quiescent normal rat kidney (NRK) cells. Herein, we demonstrated that in addition to these factors exposure to tobacco may be responsible for increased levels of PI Synthase. The biological and clinical significance of PI Synthase overexpression in human cancers remains unknown. However, PI Synthase has been shown to be essential for progres- 
Table 1: Analysis of PI Synthase protein expression in normal oral tissues, OLs and OSCCs: Correlation with clinicopathological parameters and tobacco consumption habits

\begin{tabular}{|c|c|c|c|}
\hline Clinicopathological parameters & Total Cases & PI Synthase cytoplasmic positivity & \\
\hline & $\mathbf{N}$ & $\mathbf{n}$ & (\%) \\
\hline Normal Oral tissues (N) & 10 & 0 & \\
\hline OLs & 20 & 16 & 80 \\
\hline \multicolumn{4}{|l|}{ Differentiation } \\
\hline OLs w/o dysplasia & 15 & 11 & 73 \\
\hline Dysplasia & 5 & 5 & 100 \\
\hline Mild & 2 & 2 & \\
\hline Moderate & 2 & 2 & \\
\hline Severe & 1 & 1 & \\
\hline \multicolumn{4}{|l|}{ ^Habits } \\
\hline$\wedge$ Non Tobacco consumer & 2 & 2 & \\
\hline$\wedge$ Tobacco consumer & 10 & 8 & \\
\hline \#Tobacco chewer & 9 & 8 & \\
\hline \#Khaini (Tobacco with lime) & 4 & 4 & \\
\hline \#Gutkha & 2 & 3 & \\
\hline \#Betel Quid with tobacco & 5 & 4 & \\
\hline \#Tobacco smoking & 4 & 4 & \\
\hline \#Alcohol & 3 & 3 & \\
\hline osccs & 70 & 61 & 87 \\
\hline \multicolumn{4}{|l|}{ Differentiationa } \\
\hline WDSCC & 25 & 19 & 76 \\
\hline MDSCC & 40 & 38 & 95 \\
\hline PDSCC & 5 & 4 & 80 \\
\hline \multicolumn{4}{|l|}{ ^Habitsb } \\
\hline$\wedge$ Non Tobacco consumer & 4 & 2 & \\
\hline$\wedge$ Tobacco consumer & 17 & 17 & \\
\hline \#Tobacco chewer & 16 & 5 & \\
\hline \#Khaini (Tobacco with lime) & 14 & 14 & \\
\hline \#Gutkha & - & - & \\
\hline \#Betel Quid with tobacco & 2 & 2 & \\
\hline \#Tobacco smoking & 4 & 4 & \\
\hline \#Alcohol & 4 & 3 & \\
\hline
\end{tabular}

\#Overlapping habits; ^cases excluding TMA

a:WDSCC Vs MDSCC + PDSCC $(p=0.005)$; $\mathbf{b}$ : tobacco consumer Vs non-consumer $(p=0.03, O R=9.0)$ 


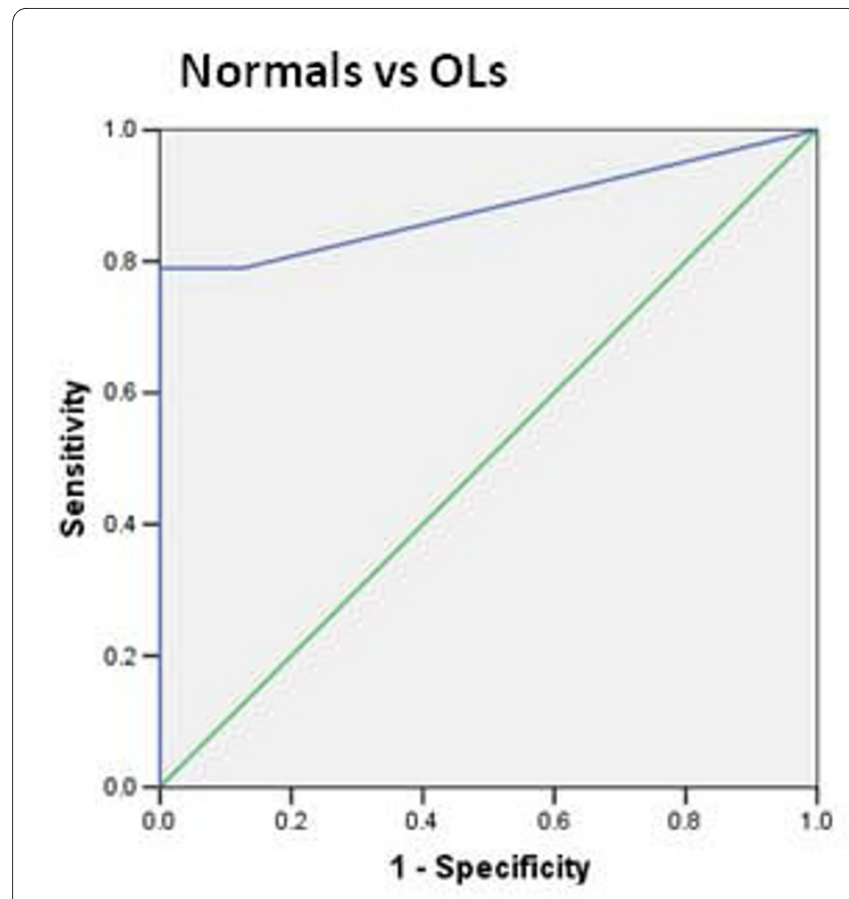

a

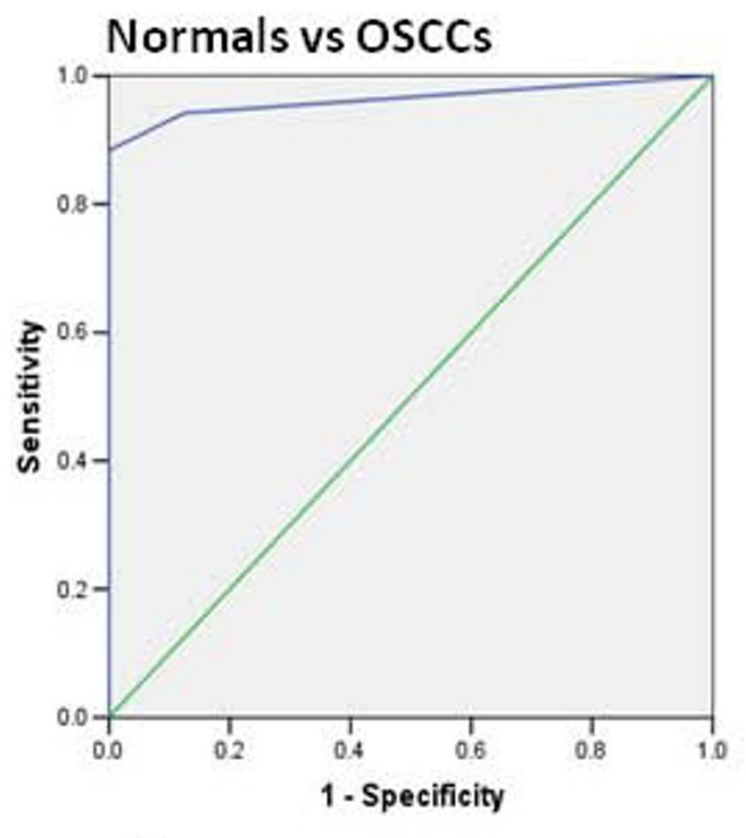

b

Figure 8 Receiver operating characteristic curves of PI Synthase.- a) normal vs OLs; b) normal vs OSCCs.

sion through $G_{1}$ phase of cell cycle [26], mainly by increasing the cellular levels of cyclins D1 and E [27]. Previous studies $[25,28,29]$ have shown that inhibitors of PI Synthase, inostamycin and $\delta$-hexachloro-cyclohexane inhibit PI synthesis and blocked cell cycle progression in the $G_{1}$ or $S$ phase respectively. Inostamycin caused decrease in the cellular levels of cyclins D1 and E [25] and suppressed the invasion ability by reducing productions of matrix metalloproteinase- 2 and -9 and cell motility in HSC-4 tongue carcinoma cell line [30].

Hence, we propose that increased PI Synthase expression could play a role in cell transformation through the increased expression of cyclin D1, and possibly other growth-enhancing effects. PI Synthase increased the cellular levels of Akt kinase in serum-stimulated quiescent NIH3T3 cells, decreased doubling time and potentiated colony formation in soft agar [27]. Since the over expression of PI Synthase in NIH3T3 cells increased PI synthesis and the amounts of PIP-2 and PIP-3, it is possible that PI Synthase overexpression also enhances cellular levels of PIP-2 and PIP-3, which, together with serum, cause increased activation of Akt kinase. The PI3-K/Akt pathway not only regulates the transcriptional activity of cyclin D1, but also increases it accumulation by inactivating glycogen synthase kinase-3 (GSK3), which targets cyclin D1 for proteasomal degradation. Since PI Synthase overexpression enhances Akt kinase activation, this could explain the increased expression of the cyclin D1 protein. West et al. [31] showed that tobacco carcinogen (NNK) induced cellular transformation and increased the activation of phosphatidylinositol 3'-kinase/Akt pathway in vitro and in vivo in lung tumorigenesis. Zheng et al. [32] demonstrated that nicotine induced PI3-K overexpression in lung cancer cells. Taken together, it suggests that upregulation of PI Synthase by ST may be one of the mechanisms by which ST exerts its effects on the PI-3 kinase pathway and other proteins involved in cellular proliferation such as cyclin D1 (Figure 9).

Immunohistochemical analysis of PI Synthase was performed in an oral cancer tissue microarray and few individual clinical samples of OLs, OSCCs and normal oral tissues. Significant increase in PI Synthase expression in lesions without dysplasia, dyplasias and OSCCs, suggests it to be an early event that occurs prior to development of malignancy. A salient finding of our study was the association of tobacco consumption with overexpression of PI Synthase in OSCCs. These clinical findings suggested that PI Synthase might be plausible molecular target of tobacco. Besides, PI3-K, has been implicated in the development and progression of numerous neoplasias including OSCCs [33,34]. Stahl et al. [35] suggested PI3-K as a marker of malignancy and tumor invasion and a potential target for pharmacological intervention in Head and Neck cancers. 


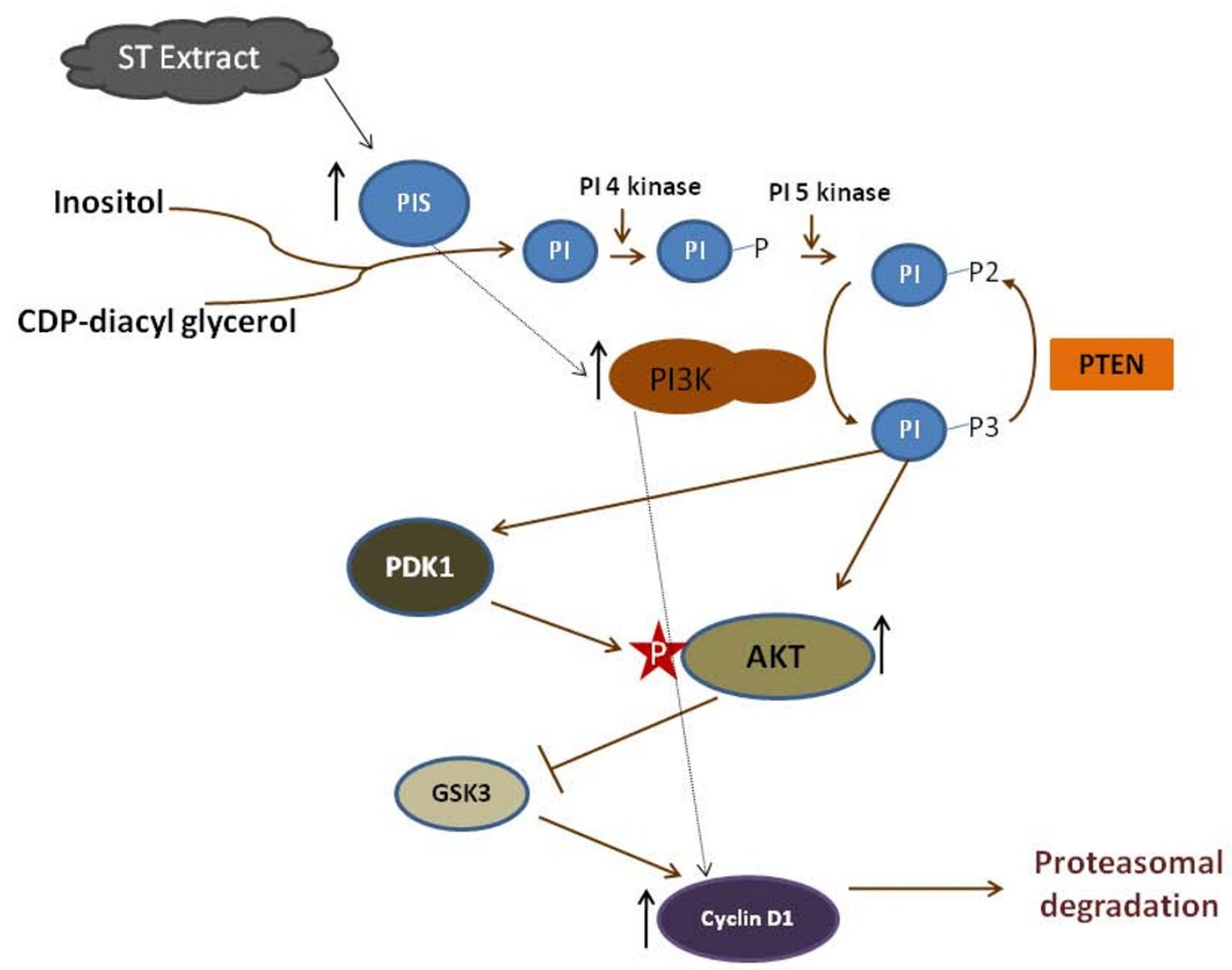

Figure 9 Depicts the proposed signaling pathway on the basis of information accrued by the current study and available literature. PIS: Phosphatidylinositol Synthase, PI3K: Phosphatidylinositol 3 Kinase, PI: Phospatidyinositol, PDK1: Phosphoinositide-Dependent Protein Kinase 1, GSK3: Glycogen Synthase Kinase 3, PTEN: Phosphatase and Tensin homolog, AKT: v-Akt Murine Thymoma Viral Oncogene Homolog 1

\section{Conclusions}

In conclusion, our in vitro studies showed increased PI Synthase, Cyclin D1 and PI3-K expression on exposure to ST in oral cell systems. In clinical samples, increased PI Synthase expression was found to be an early event in oral tumorigenesis, and is sustained during the development and progression of OSCC and is associated with tobacco consumption. These findings underscore its validation as a candidate diagnostic biomarker in oral cancer. Large-scale studies are warranted to further evaluate PI Synthase's potential as an indicator of progression risk in leukoplakia and a role in development and progression during early stages oral tumorigenesis.

\section{Abbreviations}

MDSCC: Moderately Differentiated Squamous Cell Carcinoma; OPL: Oral Precancerous Lesion; OSCC: Oral Squamous Cell Carcinoma; PDSCC: Poorly Differentiated Squamous Cell Carcinoma; ST: Smokeless Tobacco; STE: Smokeless Tobacco Extract; TNF-alpha: Tumor Necrosis Factor-alpha; WDSCC: Well Differentiated Squamous Cell Carcinoma; DMEM: Dulbecco's modified Eagle medium.

\section{Competing interests}

The authors declare that they have no competing interests.

\section{Authors' contributions}

MS and JK both carried out the experimental work, data analysis and drafted the manuscript. study. MS, JK and SDG evaluated the H\&E stained and immunostained slides. NKS and AS provided the clinical specimens for this study clinical perspective and the follow-up data. RR conceived the study, participated in its design and coordination, provided infrastructural and financial support and edited the manuscript. All authors read and approved the final manuscript.

\section{Acknowledgements}

This work was supported by research grant from the Department of Biotechnology, India. M.S is a recipient of Fellowships of the Council of Scientific and Industrial Research, India. PI Synthase antibody was provided as a kind gift from Dr. Jackowski, St. Jude Children's Hospital, Tennesee, Memphis. RR gratefully acknowledges support from the Joseph and Mildred Sonshine Centre for Head and Neck Diseases, Alex and Simona Shnaider Research Laboratory in Molecular Oncology, Temmy Latner/Dynacare, and the Department of Otolaryngology-Head and Neck Surgery, Mount Sinai Hospital, University of Toronto. 


\section{Author Details}

1Department of Biochemistry, All India Institute for Medical Sciences, Ansari Nagar, New Delhi -1 10029, India, 2Department of Pathology, All India Institute for Medical Sciences, Ansari Nagar, New Delhi -110029, India, ${ }^{3}$ Department of Surgical Oncology, Institute of Rotary Cancer Hospital, All India Institute for Medical Sciences, Ansari Nagar, New Delhi -1 10029, India, ${ }^{4}$ Department of Surgical Disciplines, All India Institute for Medical Sciences, Ansari Nagar, New Delhi -1 10029, India, 5Joseph \& Mildred Sonshine Family Centre for Head \& Neck Disease, Mount Sinai Hospital, ${ }^{6}$ Department of Otolaryngology-Head and Neck Surgery, Mount Sinai Hospital, ${ }^{7}$ Department of Pathology and Laboratory Medicine, Mount Sinai Hospital, Joseph \& Wolf Lebovic Health Complex, 600 University Avenue, Room 6-500, Toronto, Ontario, Canada M5G 1X5, ${ }^{8}$ Department of Otolaryngology-Head and Neck Surgery, University of Toronto; Toronto, Ontario, Canada M5G 2N2 and ${ }^{9}$ Department of Chemistry and Centre for Research in Mass Spectrometry, CB- Room 246, York University, 4700 Keele Street, Toronto, Ontario, Canada M3J 1P3

Received: 7 August 2009 Accepted: 28 April 2010 Published: 28 April 2010

\section{References}

1. Sano D, Myers JN: Metastasis of squamous cell carcinoma of the oral tongue. Cancer Metastasis Rev 2007, 26(3-4):645-662

2. Jemal A, Siegel R, Ward E, Hao Y, Xu J, Murray T, Thun MJ: Cancer statistics, 2008. CA Cancer J Clin 2008, 58(2):71-96.

3. Parkin DM, Bray F, Ferlay J, Pisani P: Global cancer statistics, 2002. CA Cancer J Clin 2005, 55(2):74-108.

4. Kademani D: Oral cancer. Mayo Clin Proc 2007, 82(7):878-887.

5. Bettendorf O, Piffko J, Bankfalvi A: Prognostic and predictive factors in oral squamous cell cancer: important tools for planning individual therapy? Oral Oncol 2004, 40(2):110-119.

6. Bankfalvi A, Piffko J: Prognostic and predictive factors in oral cancer: the role of the invasive tumour front. J Oral Pathol Med 2000, 29(7):291-298.

7. Hecht SS: Progress and challenges in selected areas of tobacco carcinogenesis. Chem Res Toxicol 2008, 21(1):160-171.

8. Warnakulasuriya KA, Ralhan R: Clinical, pathological, cellular and molecular lesions caused by oral smokeless tobacco--a review. J Oral Pathol Med 2007, 36(2):63-77.

9. Rodu B, Jansson C: Smokeless tobacco and oral cancer: a review of the risks and determinants. Crit Rev Oral Biol Med 2004, 15(5):252-263.

10. Scully C, Porter S: ABC of oral health. Swellings and red, white, and pigmented lesions. Bmj 2000, 321(7255):225-228.

11. Gupta PC, Mehta FS, Pindborg JJ, Bhonsle RB, Murti PR, Daftary DK, Aghi MB: Primary prevention trial of oral cancer in india: a 10-year follow-up study. J Oral Pathol Med 1992, 21(10):433-439.

12. Patel V, Hood BL, Molinolo AA, Lee NH, Conrads TP, Braisted JC, Krizman DB, Veenstra TD, Gutkind JS: Proteomic analysis of laser-captured paraffin-embedded tissues: a molecular portrait of head and neck cancer progression. Clin Cancer Res 2008, 14(4):1002-1014.

13. Ye H, Yu T, Temam S, Ziober BL, Wang J, Schwartz JL, Mao L, Wong DT, Zhou X: Transcriptomic dissection of tongue squamous cell carcinoma. BMC Genomics 2008, 9:69.

14. Radhakrishnan R, Solomon M, Satyamoorthy K, Martin LE, Lingen MW: Tissue microarray - a high-throughput molecular analysis in head and neck cancer. J Oral Pathol Med 2008, 37(3):166-176.

15. Ralhan R, Desouza LV, Matta A, Chandra Tripathi S, Ghanny S, Datta Gupta S, Bahadur S, Siu KW: Discovery and verification of head-and-neck cancer biomarkers by differential protein expression analysis using iTRAQ labeling, multidimensional liquid chromatography, and tandem mass spectrometry. Mol Cell Proteomics 2008, 7(6):1162-1173.

16. Rohatgi N, Matta A, Kaur J, Srivastava A, Ralhan R: Novel molecular targets of smokeless tobacco (khaini) in cell culture from oral hyperplasia. Toxicology 2006, 224(1-2):1-13.

17. Bussink J, Kogel AJ van der, Kaanders JH: Activation of the PI3-K/AKT pathway and implications for radioresistance mechanisms in head and neck cancer. Lancet Oncol 2008, 9(3):288-296.

18. Vivanco I, Sawyers CL: The phosphatidylinositol 3-Kinase AKT pathway in human cancer. Nat Rev Cancer 2002, 2(7):489-501.

19. Rohatgi N, Kaur J, Srivastava A, Ralhan R: Smokeless tobacco (khaini) extracts modulate gene expression in epithelial cell culture from an oral hyperplasia. Oral Oncol 2005, 41(8):806-820.
20. Sharma C, Kaur J, Shishodia S, Aggarwal BB, Ralhan R: Curcumin down regulates smokeless tobacco-induced NF-kappaB activation and COX2 expression in human oral premalignant and cancer cells. Toxicology 2006, 228(1):1-15.

21. Sawhney M, Rohatgi N, Kaur J, Shishodia S, Sethi G, Gupta SD, Deo SV, Shukla NK, Aggarwal BB, Ralhan R: Expression of NF-kappaB parallels COX-2 expression in oral precancer and cancer: association with smokeless tobacco. Int J Cancer 2007, 120(12):2545-2556.

22. Deguchi A, Imoto M, Umezawa K: Inhibition of G1 cyclin expression in normal rat kidney cells by inostamycin, a phosphatidylinositol synthesis inhibitor. J Biochem 1996, 120(6):1118-1122.

23. Arora S, Kaur J, Sharma C, Mathur M, Bahadur S, Shukla NK, Deo SV, Ralhan R: Stromelysin 3, Ets-1, and vascular endothelial growth factor expression in oral precancerous and cancerous lesions: correlation with microvessel density, progression, and prognosis. Clin Cancer Res 2005, 11(6):2272-2284

24. Warnakulasuriya S, Reibel J, Bouquot J, Dabelsteen E: Oral epithelial dysplasia classification systems: predictive value, utility, weaknesses and scope for improvement. J Oral Pathol Med 2008, 37(3):127-133.

25. Imoto M, Taniquchi Y, Fujiwara H, Umezawa K: Enhancement of CDPDG:inositol transferase activity in src- and erbB2-transformed cells. Exp Cell Res 1994, 212(1):151-154.

26. Nikawa J, Kodaki T, Yamashita S: Primary structure and disruption of the phosphatidylinositol synthase gene of Saccharomyces cerevisiae. J Biol Chem 1987, 262(10):4876-4881.

27. Deguchi A, Segawa K, Hosaka K, Weinstein IB, Umezawa K: Overexpression of phosphatidylinositol synthase enhances growth and G1 progression in NIH3T3 cells. Jpn J Cancer Res 2002, 93(2):157-166

28. Baba Y, Tsukuda M, Mochimatsu I, Furukawa S, Kagata H, Nagashima Y, Koshika S, Imoto M, Kato Y: Cytostatic effect of inostamycin, an inhibitor of cytidine 5'-diphosphate 1,2-diacyl-sn-glycerol (CDP-DG): inositol transferase, on oral squamous cell carcinoma cell lines. Cell Biol Int 2001, 25(7):613-620

29. Imoto M, Taniguchi Y, Umezawa K: Inhibition of CDP-DG: inositol transferase by inostamycin. J Biochem 1992, 112(2):299-302.

30. Baba Y, Tsukuda M, Mochimatsu I, Furukawa S, Kagata H, Yoji , Nagashima, Sakai N, Koshika S, Imoto M, et al: Inostamycin, an inhibitor of cytidine 5'-diphosphate 1,2-diacyl-sn-glycerol (CDP-DG): inositol transferase, suppresses invasion ability by reducing productions of matrix metalloproteinase- 2 and -9 and cell motility in HSC-4 tongue carcinoma cell line. Clin Exp Metastasis 2000, 18(3):273-279.

31. West KA, Linnoila IR, Belinsky SA, Harris CC, Dennis PA: Tobacco carcinogen-induced cellular transformation increases activation of the phosphatidylinositol 3'-kinase/Akt pathway in vitro and in vivo. Cancer Res 2004, 64(2):446-451.

32. Zheng Y, Ritzenthaler JD, Roman J, Han S: Nicotine stimulates human lung cancer cell growth by inducing fibronectin expression. Am J Respir Cell Mol Biol 2007, 37(6):681-690.

33. Sheng H, Shao J, Townsend CM Jr, Evers BM: Phosphatidylinositol 3kinase mediates proliferative signals in intestinal epithelial cells. Gut 2003, 52(10):1472-1478.

34. Fenic I, Steger K, Gruber C, Arens C, Woenckhaus J: Analysis of PIK3CA and $A k t / p r o t e i n ~ k i n a s e ~ B$ in head and neck squamous cell carcinoma. Oncol Rep 2007, 18(1):253-259.

35. Stahl U, Wenk J, Wagener F, Woenckhaus J, Gamerdinger U, Battmann A, Dreyer T: [Phosphoinositide 3-kinase (PI3-K) expression. Tumorigenesis of epithelial carcinoma of the mouth]. Pathologe 2004, 25(1):31-37.

\section{Pre-publication history}

The pre-publication history for this paper can be accessed here: http://www.biomedcentral.com/1471-2407/10/168/prepub

doi: $10.1186 / 1471-2407-10-168$

Cite this article as: Kaur et al., Clinical significance of Phosphatidyl Inositol Synthase overexpression in oral cancer BMC Cancer 2010, 10:168 